See discussions, stats, and author profiles for this publication at: https://www.researchgate.net/publication/352644125

\title{
The potential of chalcone-capped gold nanoparticles for the management of diabetes mellitus
}

\author{
Article $\cdot$ June 2021
}

DOI: 10.1016/.j.surfin.2021.101251

CITATIONS

10 authors, including:

Akeem Omolaja Akinfenwa

Cape Peninsula University of Technology

3 PUBLICATIONS O CITATIONS

SEE PROFILE

Sylvester Omoruy

University of the Western Cape

31 PUBLICATIONS 120 CITATIONS

SEE PROFILE

\section{READS}

98

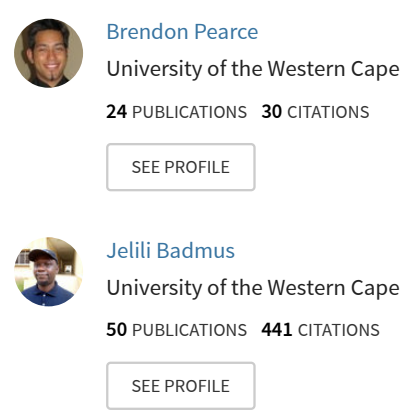

Some of the authors of this publication are also working on these related projects:

Antiviral, antibacterial and cytotoxic activities of South African plants containing cardiac glycosides View project

Subchronic exposure to silver nanoparticles disrupt lipid metabolic dynamics in male wistar rats View project 


\title{
The potential of chalcone-capped gold nanoparticles for the management of diabetes mellitus
}

\author{
Akinfenwa A. Omolaja ${ }^{\mathrm{a}}$, Brendon Pearce ${ }^{\mathrm{b}}$, Sylvester I. Omoruyia ${ }^{\mathrm{a}}$, Jelili A. Badmus ${ }^{\mathrm{c}}$, \\ Enas Ismail $^{\mathrm{a}, \mathrm{f}}$, Jeanine Marnewick ${ }^{\mathrm{c}}$, Subelia Botha ${ }^{\mathrm{d}}$, Mongi Benjeddou ${ }^{\mathrm{b}}$, Okobi E. Ekpob ${ }^{\mathrm{e}}$, \\ Ahmed A. Hussein ${ }^{\text {a, }}$ \\ ${ }^{a}$ Department of Chemistry, Cape Peninsula University of Technology, Symphony Rd. Bellville 7535, South Africa \\ ${ }^{\mathrm{b}}$ Precision Medicine Laboratory, Department of Biotechnology, 2nd Floor, Life Science Building, University of the Western Cape, Cape Town 7530, South Africa \\ ${ }^{\mathrm{c}}$ Applied Microbial and Health Biotechnology Institute, Cape Peninsula University of Technology, Symphony Rd. Bellville, 7535, South Africa \\ ${ }^{\mathrm{d}}$ Electron Microscope Unit, University of the Western Cape, Bellville, 7535, South Africa \\ ${ }^{\mathrm{e}}$ Department of Anatomy and Cellular Biology, College of Medicine and Health Sciences, Khalifa University, Abu Dhabi P.O. Box 127788, United Arab Emirates \\ ${ }^{\mathrm{f}}$ Physics department, Faculty of Science (Girl's Branch), Al Azhar University, Cairo, Egypt
}

\section{A R T I C L E I N F O}

\section{Keywords:}

Helichrysum foetidum

Chalcones

Gold nanoparticles

Bio-reduction

$\alpha$-glucosidase

Toxicity

Glucose uptake

\begin{abstract}
A B S T R A C T
Searching for new natural bioactive capping agents represent an urgent priority in the green synthesis of metal nanoparticles. Additionaly, the biosaftey of metal nanparticles is a major concern especially in medical applications. Recently, the use of pharmacollogicaly active natural products as capping agents has been deployed to avoid toxic effects during the nanoparticles preparation and to enhance their drugability compared with convential drugs. Helichrysum foetidum is a South African medicinal plant used in folk medicine for the treatment of different human pathologies, and it is known to contain a variety of bioactive compounds. Herein, the total extract and two pure chalcones, helichrysetin and helichrysin, isolated from the same plant were successfully used to synthesize quasi-monodispersed gold nanoparticles in the size range of 2-12 nm. The bio-evaluation of samples indicated that the AuNP/capping agent conjugates are biostable, and have different biological profiles from the total extract/pure compounds. The enzymatic inhibition assays showed significant inhibition by the total extract, helichrysetin and their gold nanoparticles. Interestingly, a similar activity was observed for glucose uptake in HEK293 treated cells. On the other hand, all the tested samples relatively demonstrated no cytotoxicity when tested against the HaCaT keratinocytes. In conclusion, the study demonstrated potential enhancement of glucose uptake in mammalian kidney cells, and inhibition of carbohydrate-hydrolysing enzymes by green synthesized gold nanoparticles of $H$. foetidum. It also provides a therapeutic appraisal of AuNPs/chalcones conjugate towards the development of antidiabetes drugs derived from $H$. foetidum and its gold nanoparticles.
\end{abstract}

\section{Introduction}

Polyphenols, aromaticity and conjugated systems are characteristic of plant-based flavonoids which account for their numerous roles. These properties have been shown to exert influence on the interface between the flavonoids and cell membranes during bio evaluation as antioxidants, cytotoxicity and stress-related diseases such as diabetes and overweight [29,35]. Carbohydrate metabolism requires $\alpha$-glucosidase and $\alpha$-amylase enzymes secreted in the small intestine to hydrolyse glycoside bonds from complex carbohydrate foods at different points to produce $\alpha$-glucose as the product. Uncontrolled activities of these enzymes increase postprandial glucose that leads to an imbalance between glucose absorption in the bloodstream and insulin secretion for glucose uptake [21]. Inhibition of activities of $\alpha$-glucosidase and $\alpha$-amylase enzymes have been reported to reduce the risk of obesity, kidney failure and cardiovascular diseases during Type-2 diabetic (T2D) management [11]. Acarbose, voglibose, miglitol and metfomin are conventional antidiabetic drugs commonly prescribed to inhibit hepatic glucose

\footnotetext{
* Corresponding author.

E-mail addresses: 217305296@mycput.ac.za (A.A. Omolaja), jabadmus@lautech.edu.ng (J.A. Badmus), ismailen@cput.ac.za (E. Ismail), marnewickj@cput.ac.za

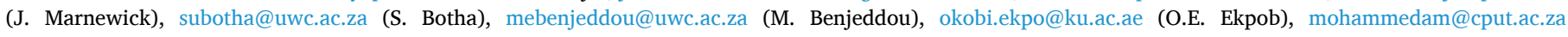
(A.A. Hussein).
} 
<smiles>COc1cc(O[C@]23OC(O)[C@H](C(O)[C@H]2O)C3O)cc(O)c1C(=O)C=Cc1ccc(O)cc1</smiles>

Compound A; Helichrysin<smiles>COc1cc(O)cc(O)c1C(=O)/C=C/c1ccc(O)cc1</smiles>

Compound B; Helichysetin

Fig. 1. Compounds A and B isolated from polar fractions of $\mathrm{H}$. foetidum.

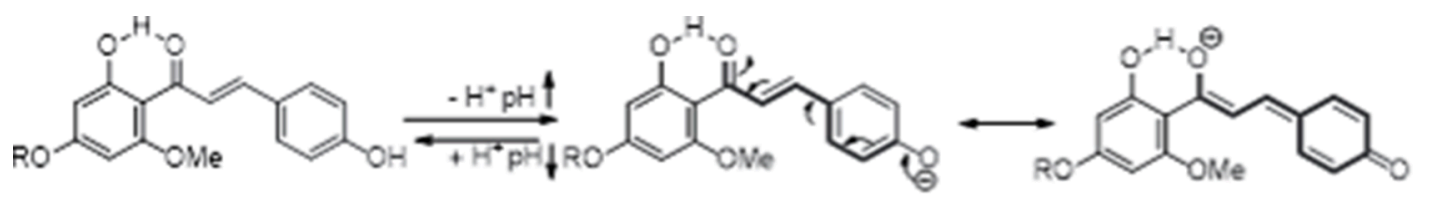

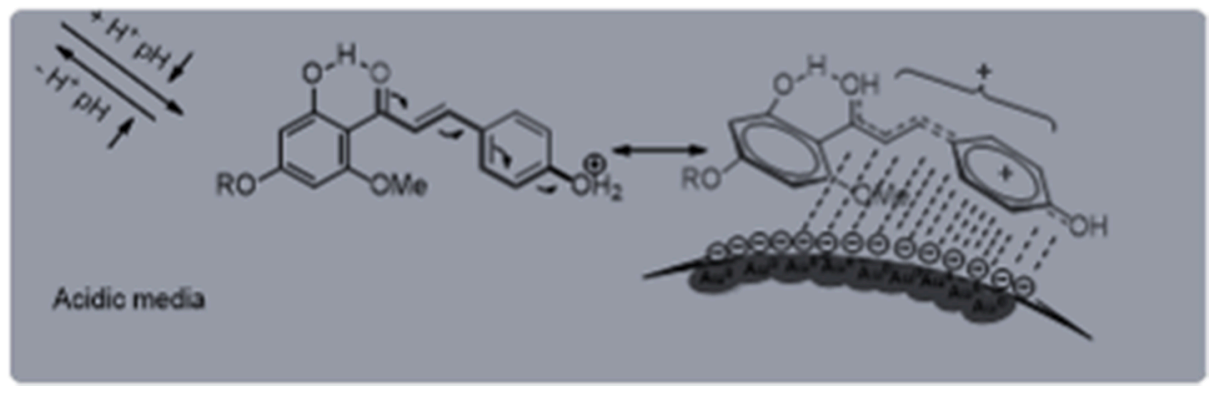

Fig. 2. Proposed interaction of the isolated compounds (capping agents) at the surface of gold nanoparticle.

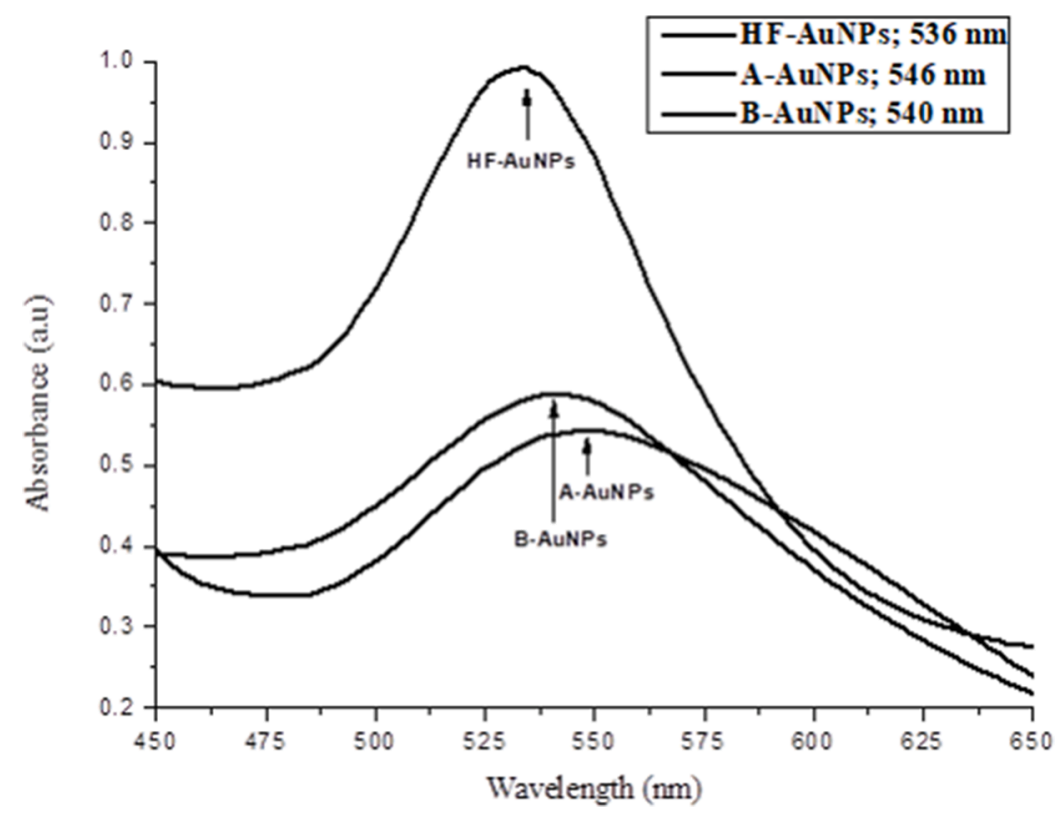

Fig. 3. UV-Vis spectra for the synthesized HF, HA and HB gold nanoparticles.

production due to the breakdown of carbohydrate by $\alpha$-glucosidase and $\alpha$-amylase enzymes [2]. However, due to the potential side effect of increasing gas build up in the intestine and liver toxicity on prolong usage [9], there is a need for the evaluation of alternative drugs in the nano range. Hence, it has become necessary to consider $\alpha$-glucosidase and amylase inhibition drugs from natural products.

Helichrysum species, also known as everlasting flowers, are widely distributed in the Southern hemisphere of Africa, Europe and Australia [4]. They are valued as medicinal plants for the treatment of ailments such as influenza, eye infection, kidney stones, relief from gastrointestinal disorders, menstrual pain, headache, wound-healing, inflammation and to induce trance [22,32]. Previous studies of the phytochemicals from $H$. foetidum demonstrated antioxidants, antimicrobial and protease-inhibiting activities [5,26,27,34]. Apart from kaur-16-en-18-oic, these phytochemicals were mostly chalcones and flavonoids (helichrysetin and its glycoside, helichrysin, apigenin and its glycoside and 7,4'-dihydroxy-5-methoxy-flavanone), which are known to have antioxidant properties, and could counteract glucose-induced oxidative stress $[18,19,26]$. Furthermore, several studies have shown a dual role of flavonoids compounds with antidiabetic potential [30] and 
(a)
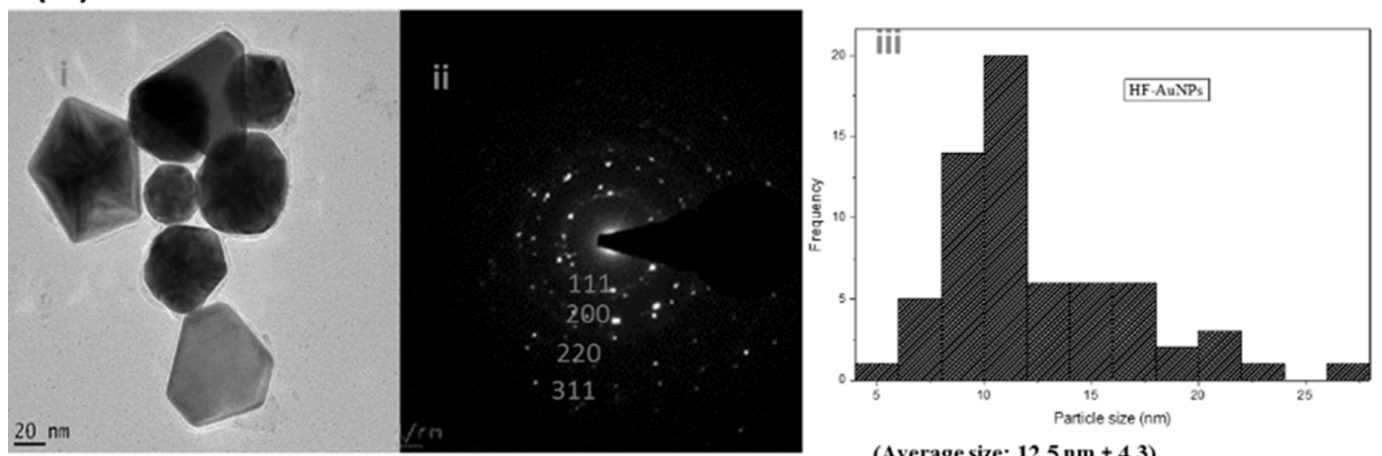

(Average size: $12.5 \mathrm{~nm} \pm 4.3$ )

(b)
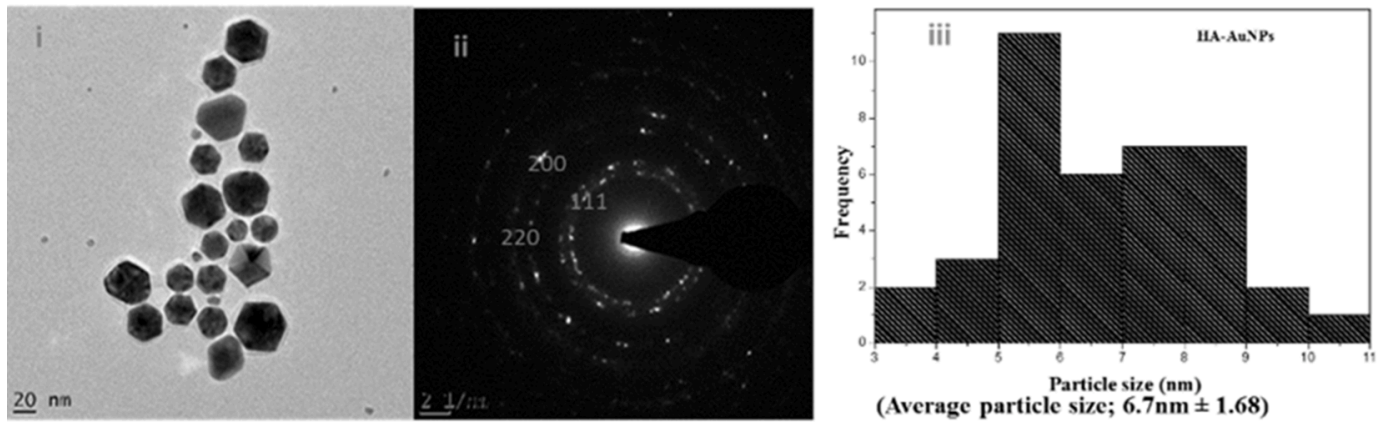

(Average particle size; $6.7 \mathrm{~nm} \pm 1.68$ )

\section{(c)}
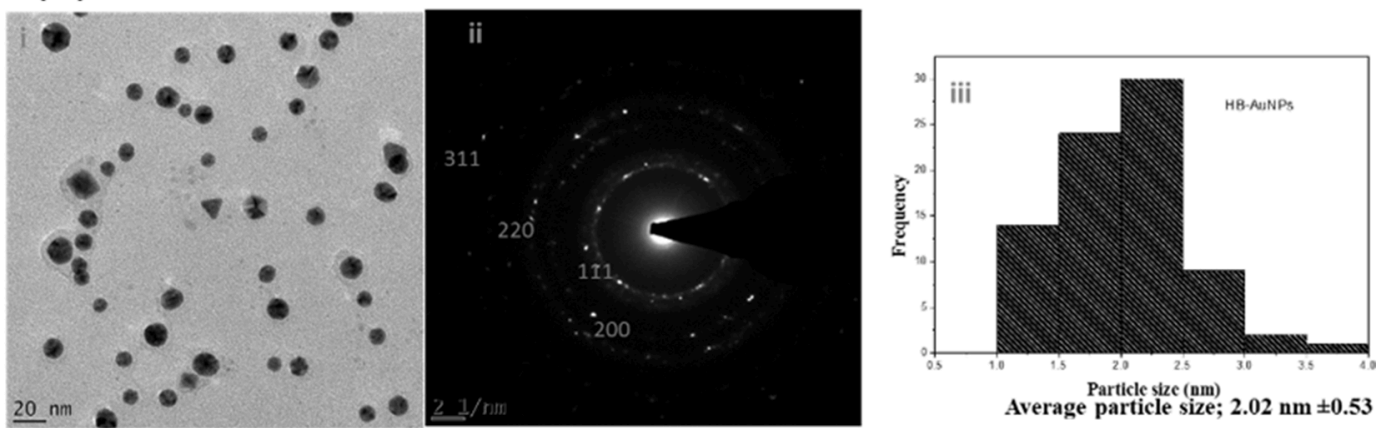

Fig. 4. a: (i) HR-TEM (ii) SAED (iii) size distribution histogram of HF-AuNPs b: (i) HR-TEM (ii) SAED (iii) size distribution histogram of compound A-AuNPs c: (i) HR-TEM (ii) SAED (iii) size distribution histogram of compound B-AuNPs.

as reducing agents in the formation of gold nanoparticles [6,14,28]. Among other metal nanoparticles, gold nanoparticles are increasingly being used in biomedicine and therapeutics due to their large surface area, biocompatibility and ease to be functionalized with biomolecules for active drug delivery [25,31]. This property of gold nanoparticles may help to overcome the possible removal of drugs from the systemic circulation by activities of the spleen and the liver. The synthesis of functionalized gold nanoparticles using total extracts of Cassia auriculate for treatment of diabetes mellitus has been previously reported [36]. However, the use of pure compounds could give a better understanding of the mechanism of formation and surface interface of flavonoid-mediated metallic nanoparticles [3,33,38].

Hence, in this report, the green synthesis of gold nanoparticle via $\mathrm{H}$. foetidum total extract and its isolated pure compounds is presented. The total extract, the isolates and the biosynthesized gold nanoparticles were characterized, and evaluated in vitro for glucose uptake and cytotoxicity. To the best of our knowledge, this is the first study to report the green synthesis of gold nanoparticles via $H$. foetidum constituents, and to evaluate their potential use in the management of diabetes.

\section{Materials and methods}

\subsection{Plant material}

Helichrysum foetidum was collected from Worcester in November 2018 and identified by Professor Cupido, department of Botany, Fort Hare University, South Africa. The fresh plant materials were left to dry in shade for four weeks before extraction.

\subsection{Chemicals and reagents}

All chemicals were analytical grade. Methanol, hexane, dichloromethane, ethanol, acetone, ethyl acetate, sodium hydroxide and sodium chloride were purchased from Science World Chemicals, South Africa. 


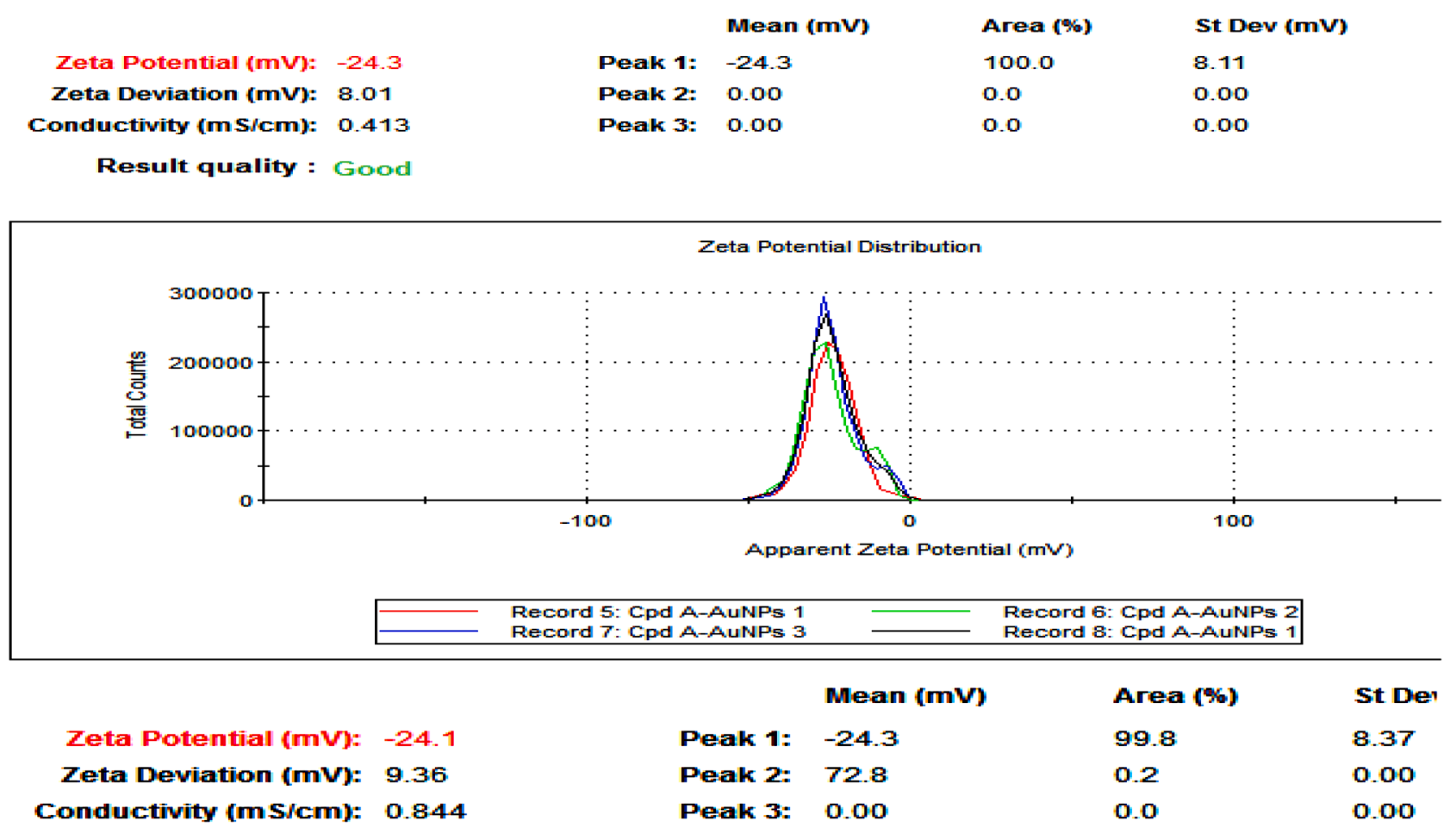

Result quality : Good

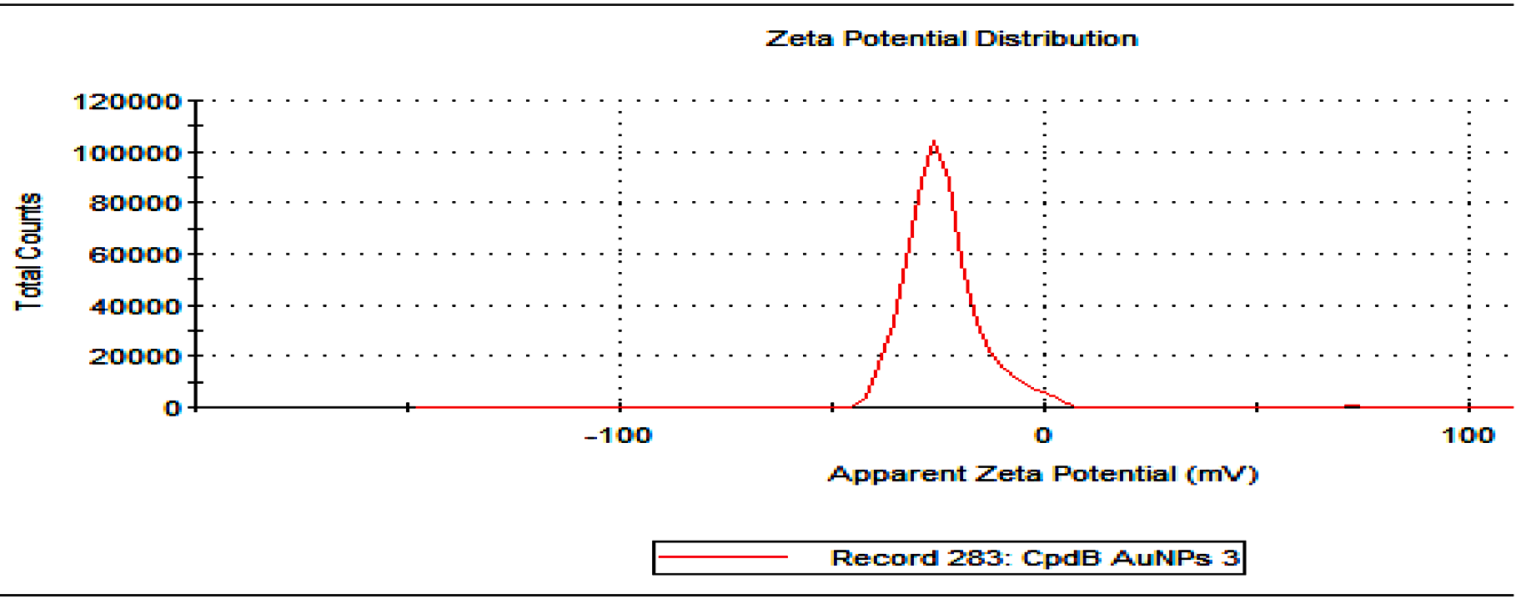

Fig. 5. i: Representative Zeta potential of compound A-AuNPs

ii: Representative Zeta potential of compound B-AuNPs.

Sodium tetrachloroaurate (III) dihydrate $\left(\mathrm{Na}_{2} \mathrm{AuCl}_{4} \cdot 2 \mathrm{H}_{2} \mathrm{O}, 99.99 \%\right)$ was purchased from BDH Chemical Limited England. Silica gel 60 (0.063$0.200 \mathrm{~mm}$ ) and Sephadex (LH-20) were supplied by Merck (Darmstadt, Germany) and Sigma-Aldrich (Cape Town, WC, South Africa) respectively. Cysteine, glycine, bovine serum albumin (BSA), $\alpha$-glucosidase (Saccharomyces cerevisiae), 4-nitrophenyl $\alpha$-D-glucopyranoside (P-NPG), and 3,5-dinitro salicylic acid (DNS) were purchased from Sigma-Aldrich (St. Louis, MO United States). The NMR spectra were recorded on an Avance $400 \mathrm{MHz}$ NMR spectrometer (Bruker, Rheinstetten, Germany) in deuterated acetone. Milli-Q de-ionized water was produced in-house $\left(18.2 \mathrm{M} \Omega \bullet \mathrm{cm}\right.$ at $\left.25^{\circ} \mathrm{C}\right)$, was used.

\subsection{Cell culture and treatment}

Renocytes (HEK293 kidney cells) were obtained from the American Type Culture Collection (Manassas, VA, USA), and were cultured in
DMEM containing essential amino acids, sodium pyruvate and L-glutamine. Cell seeding was done on 24-well plates (50 000 cells/well) for the 2-deoxy- $\left[{ }^{3} \mathrm{H}\right]$-D-glucose assay (Promega, Madison, WI, USA). The HaCaT keratinocyte cell line from the human skin was a generous donation by the Mintek Laboratory, Department of Biotechnology, University of the Western Cape. Cells were cultured in monolayer using Dulbeco Modified Eagles Medium (DMEM, Lonza Group Ltd., Verviers, Belgium) supplemented with $10 \%$ foetal bovine serum (FBS, Gibco, Life Technologies Corporation, Paisley, UK) and $1 \% 100 \mathrm{U} / \mathrm{mL}$ penicillin and $100 \mu \mathrm{g} / \mathrm{mL}$ (Lonza Group Ltd. Verviers, Belgium). Cells were grown at $37^{\circ} \mathrm{C}$, in a humidified atmosphere consisting of 5\% CO2 and 95\% air. All cell culture media were routinely replaced every two to three days and were subcultured when they attained $80 \%$ confluency using a solution of $0.25 \%$ trypsin EDTA (Lonza Group Ltd., Verviers, Belgium). Mycoplasma test was also conducted at intervals and only cells that were mycoplasma free were used for experiments. 


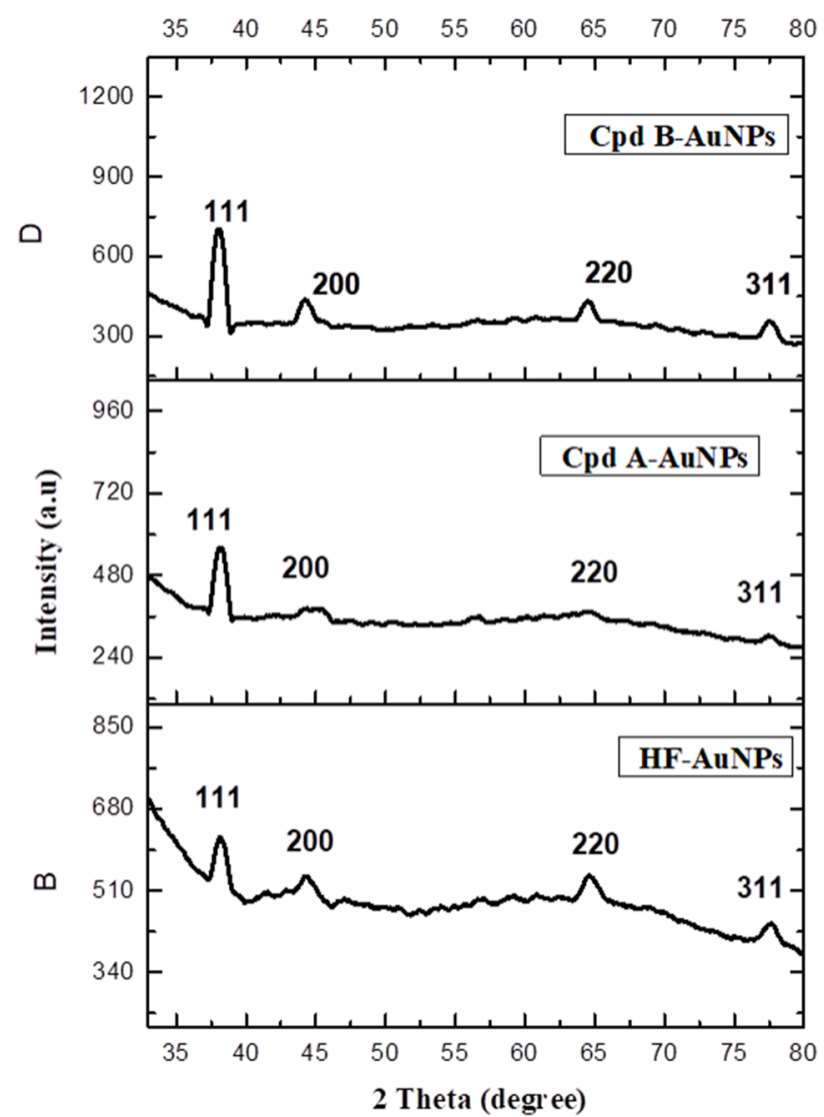

Fig. 6. X-ray diffractograms (Scintage instrument) collected from a single crystal of compound B-AuNPs, Compound A-AuNPs and HFAuNPs.

For treatment, a $1 \mathrm{mg} / \mathrm{mL}$ stock solution of extract, compounds and nanoparticles was prepared in distilled water and further dilutions were made in cell growth medium to obtain final concentrations of 20,40, 60 80 and $100 \mu \mathrm{g} / \mathrm{mL}$ used for the treatment.

\section{Experimental}

\subsection{Extraction, isolation and characterization of compounds}

Air-dried leaves and flowers of $H$. foetidum weighing $620 \mathrm{~g}$ were chopped, coarsely powdered and completely extracted with methanol (5 litres) for 48 hours at room temperature. The supernatant liquid was carefully decanted, filtered and concentrated. A dried dark yellowish crude extract $(79.87 \mathrm{~g}$ ) was obtained. The crude extract was fractionated by silica gel column $(40 \times 8 \mathrm{~cm})$ chromatography using a solvent gradient system in order of increase polarity using hexane and ethyl acetate. Fractions of $500 \mathrm{~mL}$ were collected, and similar fractions were further combined to 18 sub-fractions labelled F1 - F18 based on similarities of TLC profiles. Successive column chromatography of F9 and F16 lead to the isolation of two compounds; helichrysetin (compound B) and helichrysin (compound A) and their structures were characterized based on the analysis of their 1D and 2D NMR.

Spectroscopic data of compounds $\mathbf{A}$ and $\mathbf{B}$

Compound A; Helichrysin (6'-methoxy-2`,4-dihydroxy-chalcone4`-O- $\beta$-D-glucopyranoside): ${ }^{1} \mathrm{H}$ NMR (400 MHz, acetone- $d_{6}$ ): $\delta_{\mathrm{H}} 7.88$ $(1 \mathrm{H}, \mathrm{d}, J=15.6 \mathrm{~Hz}, \mathrm{H} \alpha), 7.77(1 \mathrm{H}, \mathrm{d}, J=15.6 \mathrm{~Hz}, \mathrm{H} \beta), 7.62(2 \mathrm{H}, \mathrm{d}, J=$ $\left.8.4 \mathrm{~Hz}, \mathrm{H} 2^{`}\right), 6.93\left(2 \mathrm{H}, \mathrm{d}, J=8.0 \mathrm{~Hz}, \mathrm{H} 3^{\prime}\right), 6.30(1 \mathrm{H}, \mathrm{d}, J=2.4 \mathrm{~Hz}, \mathrm{H} 3)$, $6.21(1 \mathrm{H}, \mathrm{d}, J=2.0 \mathrm{~Hz}, \mathrm{H} 5)$, glucose moiety; $5.13(1 \mathrm{H}, \mathrm{d}, J=7.6 \mathrm{~Hz}$, H1“), complex signals from $3.49-3.98$ for H-2“- H-6“, $4.02(3 \mathrm{H}, \mathrm{s}$, OMe). ${ }^{13} \mathrm{C}$ NMR (100 MHz, acetone- $\left.d_{6}\right): \delta_{\mathrm{C}} 193.7(\mathrm{C}=\mathrm{O}), 168.3(\mathrm{C} 4)$, 165.0 (C-2), 97.7 (C-3), 92.9 (C-5), 163.7 (C-6), 161 (C-4) ), 144.1 (C $\beta$ ),
131.5 (C-2`), 127.8 (C-1`), 124.9 (C $\alpha$ ), 116.9 (C-3`), 107.8 (C-1), 56.64 (OMe), glucose moiety; 101.00 (C-1“), 78.1 (C-5“), 77.9 (C-3“), 74.5 (C-2“), 71.3 (C-4“), 62.6 (C-6“).

Compound B; Helichrysetin (6`-methoxy-2`,4, 4`-trihydroxy-chalcone): ${ }^{1} \mathrm{H}$ NMR (400 MHz, acetone- $\left.d_{6}\right): \delta_{\mathrm{H}} 7.88(1 \mathrm{H}, d, J=15.6 \mathrm{~Hz}$, $\mathrm{H} \alpha), 7.74(1 \mathrm{H}, \mathrm{d}, J=15.6 \mathrm{~Hz}, \mathrm{H} \beta), 7.61\left(2 \mathrm{H}, \mathrm{d}, J=8.4 \mathrm{~Hz}, \mathrm{H}-2{ }^{`},-6^{`}\right)$, $6.93\left(2 \mathrm{H}, d, J=8.0 \mathrm{~Hz}, \mathrm{H}-3^{`},-5 `\right), 6.09$ (1H, s, H-5), $6.02(1 \mathrm{H}, \mathrm{s}, \mathrm{H}-3)$, $3.98(3 \mathrm{H}, \mathrm{s}, \mathrm{OMe}) .{ }^{13} \mathrm{C}$ NMR (100 MHz, acetone- $\left.d_{6}\right): \delta_{\mathrm{C}} 193.2(\mathrm{C}=\mathrm{O})$, 168.5 (C-2), 165.7 (C-4), 164.3 (C-6), 143.3 (C) 131.3 (C-6'), 128.0 (C1`), 125.3 (C $\alpha$ ), 116.8 (C-3`), 106.3 (C-1), 96.9 (C-3), 92.2 (C-5), 56.41 (OMe).

Total extract and representative fractions were then screened for glucosidase and amylase enzymes inhibition and formation of AuNPs.

\subsection{Synthesis of gold nanoparticles}

The crude extract (HF) and isolated compounds A and B were screened for green synthesis of gold nanoparticles as reducing agents, at different concentrations in a 96-well microplate for determination of the optimum concentrations and the ratio of reducing agent to the gold precursor for further upscaling. $20 \mathrm{mg}$ each of $\mathrm{HF}$, compounds A and B were dissolved separately in $2 \mathrm{~mL}$ of de-ionized water, vortexed for 5 minutes to obtain homogeneous solutions and then added dropwise to $50 \mathrm{~mL} 1 \% \mathrm{w} / \mathrm{w}$ of sodium chloroaurate (III) solution at $90{ }^{\circ} \mathrm{C}$ for 40 minutes under continuous stirring. An instantaneous colour change was observed from pale yellow to ruby red for HF and compound A. The ruby red colour appeared after 25 minutes for compound B suggesting the formation of gold nanoparticles for all samples.

\subsection{Characterization of gold nanoparticles}

Different characterization techniques such as UV, HR-TEM, XRD, FTIR, and dynamic light scattering (DLS) were used to investigate the formation of gold nanoparticles and their various physicochemical properties. The absorption bands due to electrons confined on the nanogold particles surface were measured with SPECTROstar Nano (BMG LABTECH, Germany) 2450 UV-vis spectrophotometer.

The potential stability of the gold nanoparticles was determined through zeta potential measurement and the presence of inter-particle interaction from polydispersity indices (PDI), using a Zetasizer Nanoseries ZS90, model number ZEN3690 (Malvern Instruments Ltd, UK). To determine the hydrodynamic size, gold nanoparticles were diluted in deionized water in a volume ratio of $2: 1$. The zeta potential value gives an indication of the magnitude of repulsion between particles, which is suggestive of the stability of the colloidal system while the PDI gives the size distribution of the particles.

High-Resolution Scanning Electron Microscope (HR-TEM) micrographs were recorded on an FEI Tecnai G2 F20 S-Twin HRTEM, operated at $200 \mathrm{kV}$. A drop of the aqueous gold suspension was dropped on a carbon-coated copper grid and allowed to dry completely for an hour at room temperature. X-ray diffraction (Model Bruker AXS D8 advance with radiation at $\lambda k C u k \alpha_{1}=1.5406 \AA$ ) was used to observe the crystallinity of the particles. Measurements were performed using a multipurpose X-ray diffractometer D8-Advance from Bruker operated in a continuous $\theta-\theta$ scan in locked coupled mode with $\mathrm{Cu}-\mathrm{K}_{\alpha}$ radiation. The sample was mounted in the centre of the sample holder on a glass slide and levelled up to the correct height. The measurements were performed within a range in $2 \theta$ between $30^{\circ}-80^{\circ}$ with a typical step size of $0.034^{\circ}$ in $2 \theta$. A position-sensitive detector, Lyn-Eye, was used to record diffraction data at a typical speed of $0.5 \mathrm{sec} / \mathrm{step}$ which is equivalent to an effective time of $92 \mathrm{sec} / \mathrm{step}$ for a scintillation counter. Analysis of HR-TEM and XRD images were carried out with ImageJ software, $1.50 \mathrm{~b}$ version 1.8.0_60 (http://imagej.nih.gov/ij) and Origin pro-2019 (64 bits) software respectively. Vibrational bands of possible functional groups involved in the synthesis were recorded on a PerkinElmer FourierTransform Infrared Spectrometer 2000, equipped with a universal 

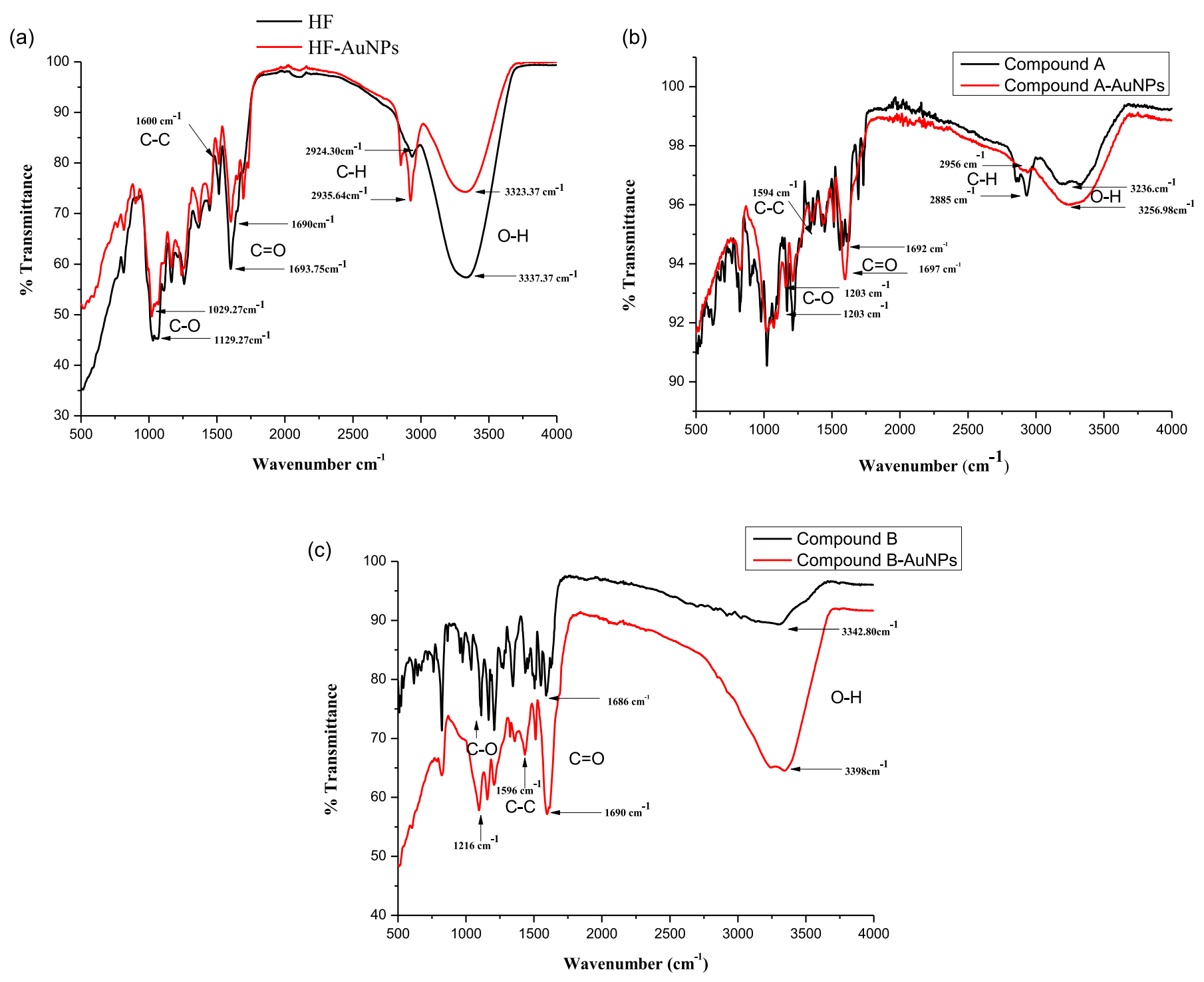

Fig. 7. a: FTIR of HF and HF-AuNPs

b: FTIR of Compound A and Compound A-AuNPs

c: FTIR of Compound B and CompoundB-AuNPs.

ATR-FTIR (PerkinElmer Spectrum 100, Llantrisant, Wales, UK) at transmission mode of $400-4000 \mathrm{~cm}^{-1}$.

\subsection{In vitro stability study}

The in-vitro stability test was carried out by mixing $200 \mu \mathrm{L}$ of gold nanoparticles solution with $100 \mu \mathrm{L}$ biogenic amino acids (such as $0.5 \%$ Glycine, $0.5 \% \mathrm{BSA}$ ), phosphate buffer saline (PBS at pH 7 and $\mathrm{pH} 9$ ) and $1 \% \mathrm{NaCl}$ solution in a 96 -well plate and incubated (at $37^{\circ} \mathrm{C}$ ) for different periods. The stability of HF-AuNPs, Compound A-AuNPs and Compound B-AuNPs in these media were monitored with UV-Vis at an interval of 24 hours for three days, for correlation of their respective maximum wavelengths with that of their synthesized gold nanoparticles.

\subsection{Enzymatic inhibition bioassay}

The inhibition potentials of $\alpha$-glucosidase and $\alpha$-amylase for HF, Compounds A, Compound B and their respective gold nanoparticles were carried out with slight modification of Badeggi et al. [3]. The samples were initially dissolved in methanol at $1 \mathrm{mg} / \mathrm{mL}$ as stock solution respectively. A 96 -well plate was set up for the reaction followed by a step-by-step pipetting of samples, buffer solution, enzymes and substrates. $50 \mu \mathrm{L}$ phosphate buffer $(100 \mathrm{mM}, \mathrm{pH}=6.8)$ was dispersed plus $10 \mu \mathrm{L} \alpha$-glucosidase enzyme ( $1 \mathrm{U} / \mathrm{mL})$ and $20 \mu \mathrm{L}$ of varying concentrations of HF $(0.0625,0.125,0.25,0.5$, and $1 \mathrm{mg} / \mathrm{mL})$ were preincubated at $37^{\circ} \mathrm{C}$ for $15 \mathrm{~min}$. Following preincubation, $50 \mu \mathrm{L}$ of $5 \mathrm{mM}$ P-NPG was added as a substrate and incubated further at $37^{\circ} \mathrm{C}$ for 20 mins. The reaction was brought to end by adding $50 \mu \mathrm{L} \mathrm{Na}_{2} \mathrm{CO}_{3}(0.1 \mathrm{M})$. The absorbance of the reaction mixture was measured at $405 \mathrm{~nm}$ using Multiplate Reader (Multiskan Thermo scientific, version 1.00.40, Vantaa, Finland) and correlated to $\alpha$-glucosidase inhibition. For the $\alpha$-amylase inhibition experiment, $\alpha$-amylase enzyme replaced $\alpha$-glucosidase enzyme, $1 \%$ starch solution was used in place of PNG and DNS in place of $0.1 \mathrm{M} \mathrm{Na}_{2} \mathrm{CO}_{3}$ in the mixtures. After the addition of $50 \mu \mathrm{L} \mathrm{DNS}$, the reaction mixtures were boiled on a steam bath at $95^{\circ} \mathrm{C}$ for 20 minutes for colour change. The same procedure was repeated for compounds A and $\mathrm{B}$ and their respective gold nanoparticles. Uninhibited solutions samples with AuNP were set up in parallel as control and each experiment was performed in triplicates. The results were expressed as percentage inhibition calculated according to the formula,

Inhibitoryactivity $(\%)=(A-B) / A \times 100$ 

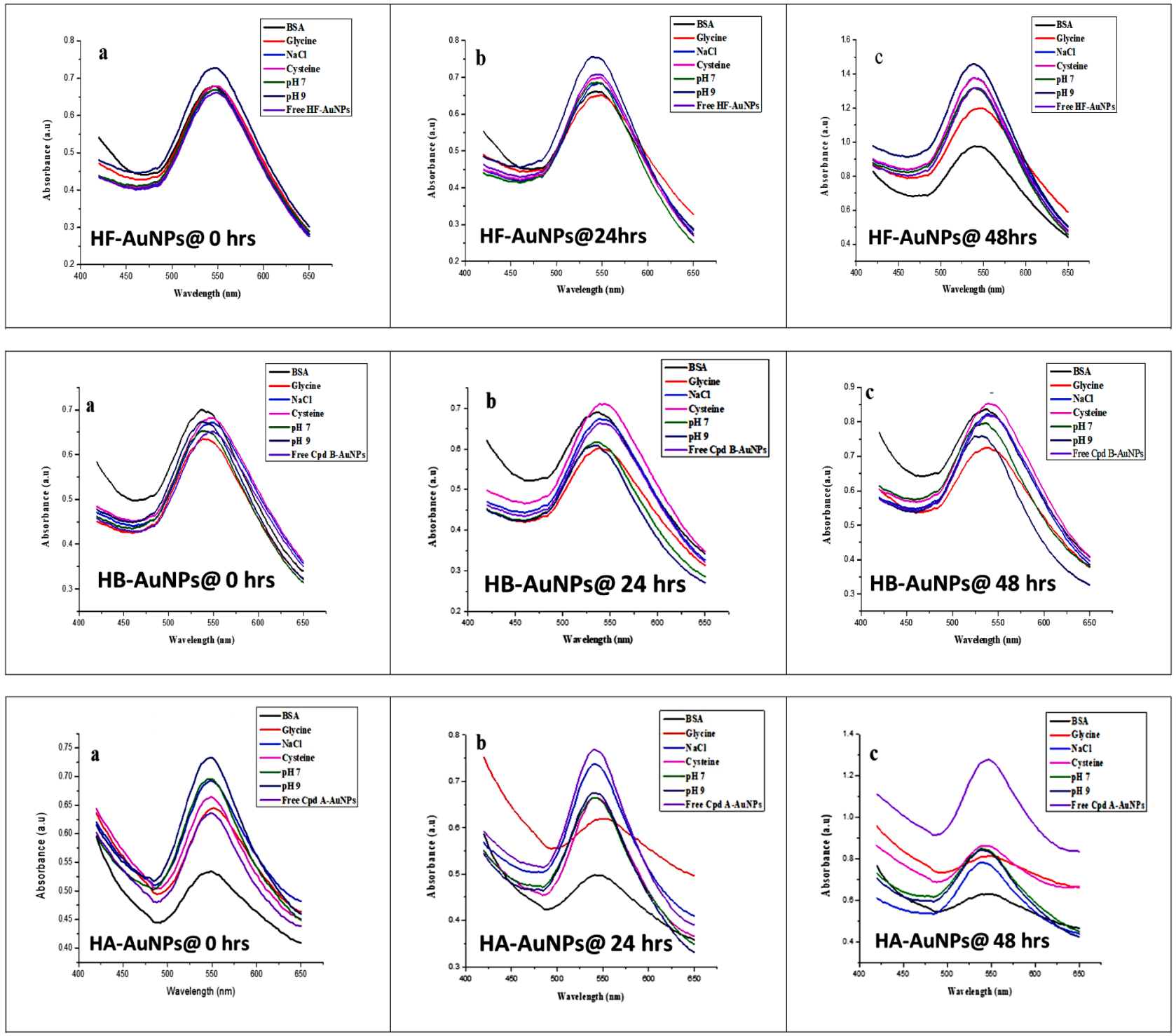

Fig. 8. i: Stability-time studies of HF-AuNPs in different biogenic media ii: Stability-time studies of HB-AuNPs in different biogenic media iii: Stability-time studies of HA-AuNPs in different biogenic media.

Table 1

Inhibitory activities of HF, isolated compounds and biosynthesized nanoparticles on alpha-glucosidase and alpha-amylase.

\begin{tabular}{lll}
\hline Sample & $\begin{array}{l}\mathrm{IC}_{50}(\mu \mathrm{g} / \mathrm{mL}) \\
\alpha \text {-Glucosidase }\end{array}$ & $\alpha$-Amylase \\
\hline HF & $27.3 \pm 0.3$ & $\mathrm{NA}$ \\
HF-AuNPs & $391.5 \pm 0.1$ & $44.46 \pm 3.3$ \\
compound A & $48.3 \pm 0.1$ & $\mathrm{NA}$ \\
compound A-AuNPs & $173.3 \pm 0.1$ & $\mathrm{NA}$ \\
compound B & $19.4 \pm 0.3$ & $25.13 \pm 0.3$ \\
compound B-AuNPs & $40.0 \pm 0.2$ & $35.6 \pm 0.1$ \\
\hline
\end{tabular}

*NA $=$ No activity

Where $\mathrm{A}=$ absorbances of uninhibited control and $\mathrm{B}=$ absorbances of test samples with inhibition agent. GraphPad Prism 5 statistical package (GraphPad Software, USA) was used for statistical analysis for the concentration of sample resulting in 50\% inhibition of the $\alpha$ - glucosidase and $\alpha$ - amylase activities $\left(\mathrm{IC}_{50}\right.$ ) respectively and results expressed in terms of mean \pm standard deviation.

\subsection{Glucose uptake assay}

The method for measuring glucose uptake in mammalian cells based on the detection of 2-deoxyglucose-6-phosphate was performed according to the manufacturer's guidelines. When cells are exposed to 2deoxyglucose (2DG), there are transported across the membrane and rapidly phosphorylated in the same manner as glucose. However, enzymes that further modify glucose-6-phosphate (G6P) cannot modify 2DG6P, and thus a membrane-impermeable analyte accumulates in the cell. After a brief period of incubation, the acidic Stop Buffer is added to lyse cells, terminate uptake and destroy any NADPH. A high-pH buffer solution (Neutralization Buffer) is then added to neutralize the acid. A Detection reagent is added to the sample wells. Glucose-6-Phosphate Dehydrogenase oxidizes the deoxyglucose to 6-phosphodeoxygluconate and simultaneously reduces NADP + to NADPH. The reductase uses NADPH to convert the proluciferin to luciferin, which is then used by Ultra-Glo ${ }^{\mathrm{TM}}$ Recombinant Luciferase to produce a luminescent signal that is proportional to the concentration of 2DG6P.

The reaction mixtures were incubated at room temperature for 1 hour. After 1 hour the cells were incubated with various concentrations 


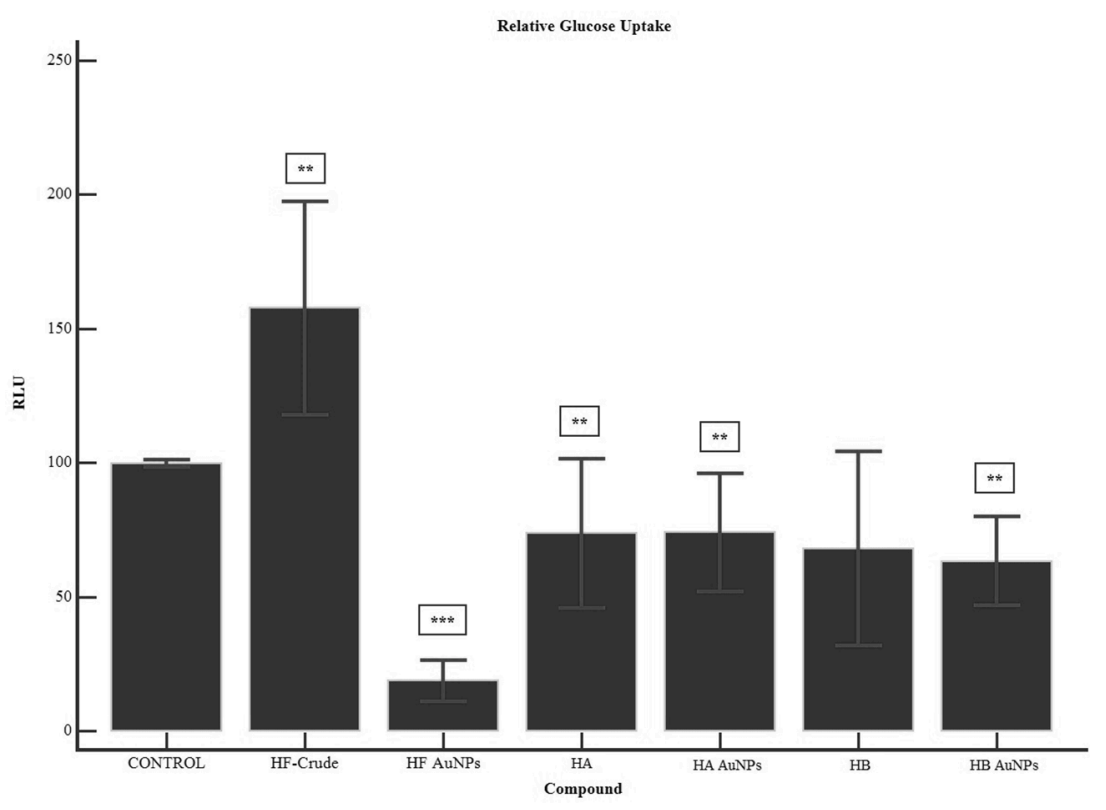

Fig. 9. Relative glucose uptake of crude extract, compounds and nanoparticles; where the p-value is indicative of the statistical significance versus the control, using an independent two-tailed T-test. ${ }^{*} \mathrm{p}=0.05,{ }^{* *} \mathrm{p}=0.005,{ }^{* * *} \mathrm{p}=0.001$.

A

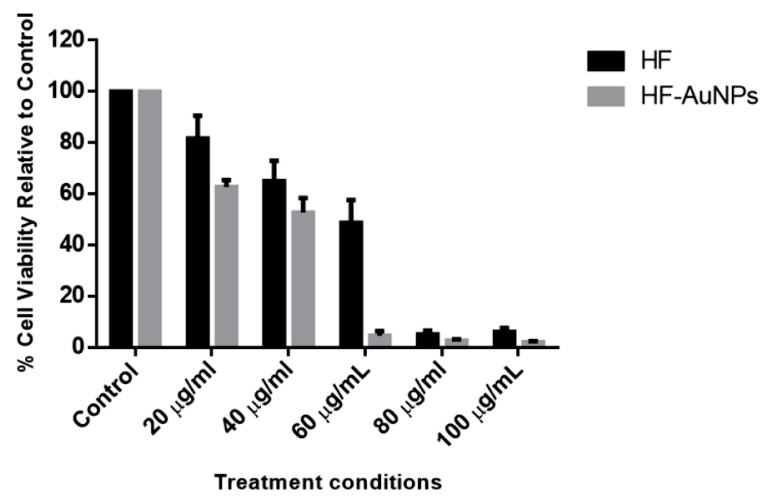

B
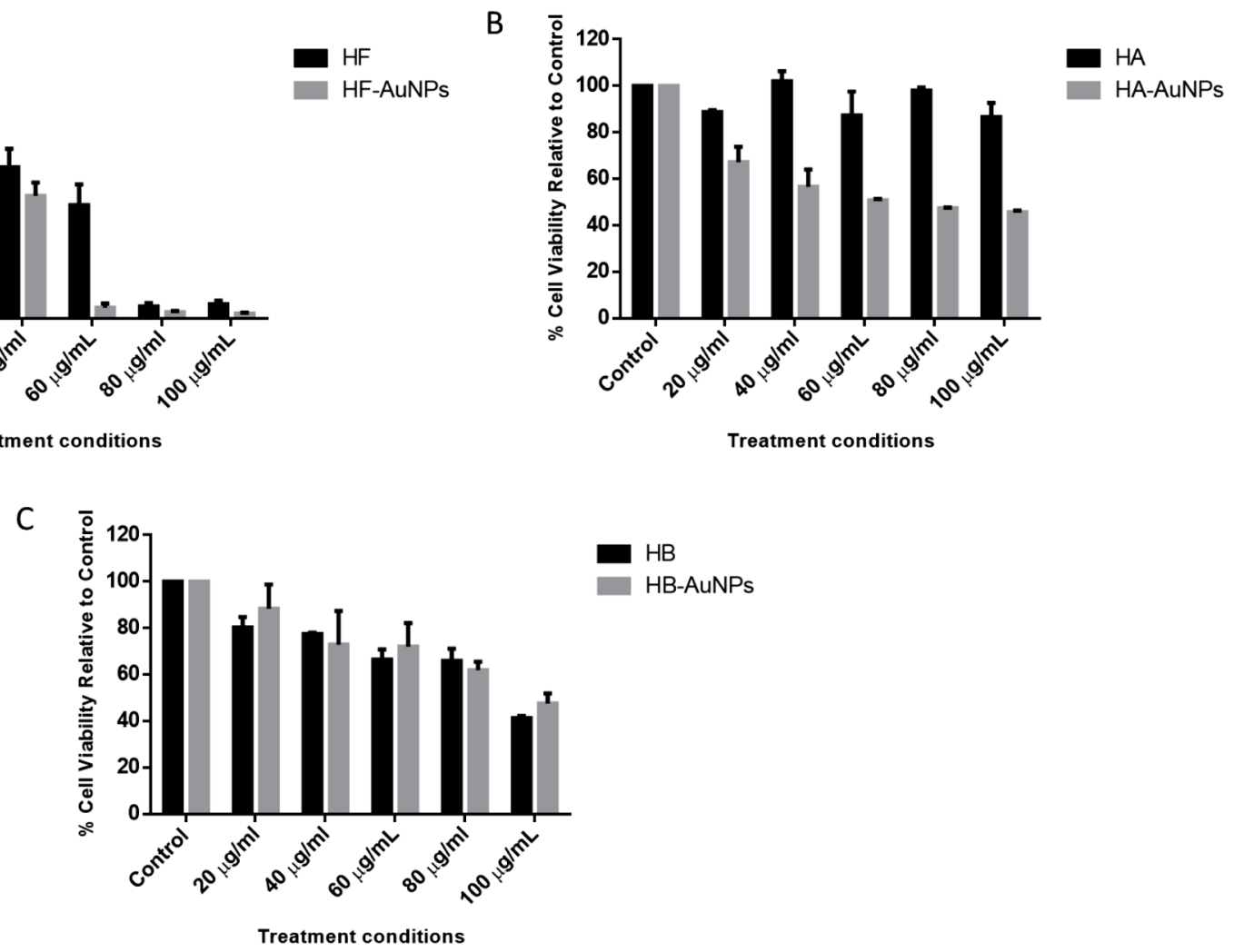

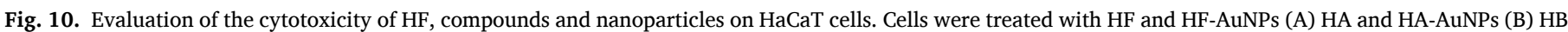

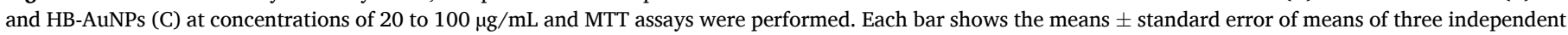
experiments performed in quadruplicates.

of each compound, the cells were washed with $100 \mu \mathrm{l}$ PBS. A volume of $50 \mu \mathrm{L} \mathrm{1mM} \mathrm{2DG} \mathrm{was} \mathrm{added} \mathrm{to} \mathrm{each} \mathrm{well} \mathrm{and} \mathrm{allowed} \mathrm{to} \mathrm{incubate} \mathrm{for} 10$ minutes. A volume of $25 \mu \mathrm{L}$ stop buffer was added to each well and shaken briefly. Thereafter, $25 \mu \mathrm{L}$ of neutralization buffer was added to each well and shaken briefly. Finally, a volume of $100 \mu \mathrm{L}$ of reductase substrate mix was added and the plate was shaken briefly. The plate was then incubated at room temperature for 30 minutes and read on a plate reader at 15 minutes intervals for 2 hours.

Fig. 7 indicates the relative glucose uptake for a given compound, compared to the control. The p-values in these graphs were calculated using an independent two-tailed T-test where 0.05 is the threshold for significance. 


\subsection{Cytotoxicity assay}

Cytotoxicity was assessed using the 3-[4,5-dimethylthiazol-2-yl]2,5diphenyltetrazolium bromide colourimetric assay (MTT, Sigma). The MTT is a yellow tetrazolium salt that is reduced to purple formazan in living cells. Briefly, the HaCaT keratinocytes were plated in 96-well cell culture plates at a cell density of 5000 cells per well and incubated overnight to allow for attachment. The medium was thereafter replaced with a fresh medium containing increasing concentrations $(20,40,6080$ and $100 \mu \mathrm{g} / \mathrm{mL}$ ) of HF, HA, HB, HF-AuNPs, HA-AuNPs and HB-AuNPs for 48 hours. Cells incubated with medium only served as control. After the 48 hours incubation, $10 \mu \mathrm{L}$ of the MTT solution $(5 \mathrm{mg} / \mathrm{mL})$ was added to each well and the cells were incubated for an additional 4 hours at $37^{\circ} \mathrm{C}$. Thereafter, the resultant MTT crystals formed were solubilized in DMSO and absorbance of each well was read at $570 \mathrm{~nm}$ using a BMG Labtech Omega ${ }^{\circledR}$ POLARStar multimodal plate reader. The percentage cell viability was calculated using the formula below:

$\%$ Cell Viability $=\frac{\text { Absorbance of treated well }}{\text { Absorbance of Untreated well }} \times 100$

The concentration required to kill $50 \%$ of the cells ( $\mathrm{IC}_{50}$ ) was determined via a survival curve using GraphPad Prism6 software (GraphPad Software, San Diego, CA, USA).

\section{Results and discussion}

\subsection{Isolation and identification of compounds}

Preliminary screening of $H$. foetidum extract for the synthesis of AuNPs [10], showed promising results, subsequently, it was subjected to purification steps to identify the compounds responsible for the reduction and stabilization of AuNPs. Chromatographic manipulation in parallel with NPs assay formation, two compounds were isolated. Structural elucidation of these compounds was completed by recording the ${ }^{1} \mathrm{H}$ and ${ }^{13} \mathrm{C}$ NMR data and compared with the literature $[7,19,23,26$, 37]. The ${ }^{1} \mathrm{H}$ and ${ }^{13} \mathrm{C}$ NMR of compounds $\mathrm{A}$ and $\mathrm{B}$ discussed in the experimental session showed identical ${ }^{1} \mathrm{H}$ and ${ }^{13} \mathrm{C}$ NMR profiles with the same compounds reported previously. Compound B was identified as 6 '-methoxy-2`,4,4`-trihydroxy-chalcone (helichrysetin), and compound $\mathrm{A}$ as $6^{`}$-methoxy-2`4-dihydroxy-chalcone-4`-O- $\beta$-D-glucopyranoside (helichrysin) a glycosylated form of HB (Fig. 1). These compounds were previously reported by [19] and [26] from the same plant [19,26]. However, the first record of these compounds from the Helichrysum genus shows that they were isolated from the flower extract of Helichrysurn ps. aff. H. cooperi Harv. and the aerial part of H. heterolasium respectively [[7],37]. Compound B was later isolated from a flower extract of $H$. odoratissimum [23], and recently reported to induce apoptosis of cancer cells [16].

\subsection{The interaction of the chalcones on the surface of gold nanoparticle}

The chemical structures of helichrysin and helichrysetin show the properties of Lewis bases due to the availability of a divalent oxygen atom, which serves as an electron donor/proton acceptor via the hydroxyl and carboxyl functional groups, as well as the presence of a conjugated double bonds system, as shown in Fig. 2. The oxidation/ reduction abilities of phenolic compounds are possible and depend on the reaction conditions [24]. In the case of chalcones, the extended chromophore supports the stability of the resulted -ve/+ve charges entity. From the practical point of view, the formation of the AuNPs is usually associated with the drop of the $\mathrm{pH}$ and the solution becomes acidic, under this condition and as given in scheme 1 , the protonation of the oxygen atoms is very possible to form a positively charged stable system. The interaction of the positively charged with the negatively charged surface metal stabilize the NPs. This proposed mechanism is supported by the highly negative potential of the NPs as indicated from
Zeta potential and the drop of the $\mathrm{pH}$ of the NPs solution

\subsubsection{Optical properties}

UV-Vis spectroscopy was used to confirm the formation of AuNPs. The solution of auric chloride, the total extracts and the two compounds, all had yellowish colours before synthesis. A visual colour change from yellowish to ruby red was the initial confirmation of AuNPs formation. This was characterized by intensely ruby red colours observed at 536 $\mathrm{nm}, 540$ and $546 \mathrm{~nm}$ bands for HF, compound A and compound B nanoparticles respectively (Fig. 3). These band absorptions were within the range reported for green mediated gold nanoparticles synthesis [25]. The absorption bands of compound A-AuNPs and compound B-AuNPs were almost similar suggestive of symmetrical sizes and shapes of their nanoparticles compared to HF-AuNPs. Worthy of note is that the formation of the nanoparticles by the extract was instantaneous with higher intensity compared to the individual compounds. Abdel-Rauf et al. [1] reported a similar rapid formation of gold nanoparticles via an extract of Galaxaura elongate [1]. This could be due to the collective effect of more than one reducing agents present in HF which enhance the reducing ability of the total extract to yield a gold nanoparticle with a higher absorption peak compared to the others. Similar peaks for gold nanoparticles were reported by Thiphe et al. [33], which supports the phytochemical reduction of the auric chloride by the flavonoid constituents of $H$. foetidum [33].

\subsubsection{Morphology and size distribution}

HR-TEM technique gives information on the size, shape and crystallinity of synthesized nanoparticles. The HR-TEM micrographs recorded for the biosynthesized gold nanoparticles clearly show nanosized and non-agglomerated particles for compound B-AuNPs, A-AuNPs, and HF-AuNPs respectively (Fig. 4a-4c). Compound B-AuNPs and compound A-AuNPs images revealed quasi-monodisperse shapes mostly hexagonal with a few spherical and triangular shapes, while HF-AuNPs exhibited varieties of shapes including spherical, triangular hexagonal, and rod shapes. Mean particles sizes from the histograms showed sizes in the range of $12.5 \pm 04.3,6.7 \pm 1.68$ and $2.02 \pm 0.53 \mathrm{~nm}$ for HF-AuNPs, compound A-AuNPs and compound B-AuNPs respectively. It is interesting to note that the pure compounds enhanced the size reduction of the AuNPs formed when compared to the crude extract. The smaller sizes of compound A-AuNPs and compound B-AuNPs compared to HFAuNPs can be attributed to the phenolic content of flavonoids that interface with the metal ions. Hence, it is suggestive that pure compounds could proffer a better size-control of nanoparticles than using total extract in the biosynthesis of gold nanoparticle. The SAED patterns (Fig. 4aii - 4cii) indicated high crystallinity of all biosynthesized gold nanoparticles and it was in strong agreement with the XRD results.

\subsubsection{Dynamic light scattering by AuNPs}

Determination of zeta potential (ZP) of nanoparticles is necessary for nano-bio materials as it gives valuable information on the degree of stability of the particles in the colloidal system [13]. The zeta potential values range between $+100 \mathrm{mV}$ to $-100 \mathrm{mV}$, however, values greater than $+25 \mathrm{mV}$ or less than $-25 \mathrm{mV}$ is considered to have a high degree of stability for low molecular weight samples [17]. Similarly, PDI measured provides information on the size distribution of particles and the level of uniformity or heterogeneity of particles sizes. PDI values less than 0.05 show high homogeneity of particles, values between 0.5-0.7 are less uniform and above 0.7 is highly polydisperse [8]. To determine the stability of our nanoparticles between the interfacial double layers of particles surface charges, the disperse medium and the PDI, a Zetasizer that measures ZP and PDI based on dynamic light scattering was used. All samples gave moderate zeta potentials of -27.1, -24.3 and $-24.1 \mathrm{mV}$ for the total extract compound A and B respectively (Fig. $5 \mathrm{i}$ and 5ii) These values indicate that formed AuNP were less prone to aggregation with a slightly higher stability of HF-AuNPs than that of the compounds. This can be attributed to possible influence of the 
polyphenols found in the total extract. Relatively high PDI values of $0.440,0.408$ and 0.320 were obtained for HF-AuNPs, Compound A-AuNPs and Compound B-AuNPs respectively. This reflects the level of uniformity of sizes of nanoparticles as seen under HR-TEM.

\subsubsection{Crystallographic structure of green mediated nanoparticles}

In addition to SAED patterns, we further confirmed the high crystallinity of all biosynthesized gold nanoparticles using X-ray diffraction measurement. Crystallographic reflection of all samples (Fig. 6) exhibited four main peaks centered at $38^{\circ}, 44^{\circ}, 65^{\circ}$ and $76^{\circ}(2 \theta)$ for HFAuNPs and $38^{\circ}, 43^{\circ}, 64^{\circ}$ and $77^{\circ}(2 \theta)$ for both compound A-AuNPs and compound B-AuNPs (supplementary data). The peaks matched with JCP2 gold number 04-0784 for 38.185, 44.393, 64.578 and 77.549 respectively. These values were attributed to crystallographic reflections that correspond to Miller indices of (111), (200), (220) and (311) planes of crystalline gold. Our result were in agreement with standard BraggBrentano geometry using $\mathrm{Cu} \mathrm{K} \alpha$ radiation and corresponded to facecentred cubic metallic gold structure [12].

\subsection{Vibrational spectroscopy}

FTIR spectra measurement showed functional groups in the constituents of $H$. foetidum involved in the bioreduction of auric chloride. Functional groups of the extract and compounds matched with those of the nanoparticles indicating that the constituent of the plant capped the AuNPs (Fig. 7a-c). Peaks from HF, compound A, compound B and their gold nanoparticles were quite similar. However, a slight shift of some bands suggests the interaction of some functional groups with the surface of the AuNPs [23]. For example, and as indicated in the figures, the most effect was observed for hydroxyl group stretching $\left(\sim 3337 \mathrm{~cm}^{-1}\right)$ and $\mathrm{C}=\mathrm{O}$ stretch $\left(1690-1697 \mathrm{~cm}^{-1}\right)$ which slightly changed from the parent compound and the AuNPs conjugates. The presence of bands at $1600 \mathrm{~cm}^{-1}$ (HF), $1594 \mathrm{~cm}^{-1}$ (Compound A) and $1596 \mathrm{~cm}^{-1}$ (Compound B) can be attributed to the C-C stretch of the aromatic (in-ring), which were slightly shifted in the reduced gold nanoparticles. Additionally, there was an enhancement to the band at $\sim 3000 \mathrm{~cm}^{-1}$, for the aromatic $\mathrm{C}-\mathrm{H}$ stretches, also, the phenolic C-O stretching vibration located at $1129 \mathrm{~cm}^{-1}, 1203 \mathrm{~cm}^{-1}$ and $1216 \mathrm{~cm}^{-1}$ in $\mathrm{HF}$, compound A and $B$ respectively. Bands were not shifted in the reduced AuNPs but appeared with different intensities. From the above discussion, the $\mathrm{OH}, \mathrm{C}=\mathrm{O}$ and aromatic rings could be the interaction points between the capping agents and the surface of Au NPs.

\subsection{Stability of AuNPs}

Fig. 8 represents the in-vitro stability-time studies for biocompatibility of the gold nanoparticles in proteinogenic amino acids (BSA, glycine, cysteine), $\mathrm{NaCl}$ solution, $\mathrm{PBS}$ at $\mathrm{pH} 7$ and $\mathrm{pH}$ 9. This is to check the time duration for nanoparticles to retain their properties without decomposition in physiological systems. Stable absorption bands of the particles were recorded at 0,24 and $48 \mathrm{hrs}$ in different biogenic media on a UV-Vis spectrophotometer. Fig. 6i-ii revealed that a stable absorption maximum at $536 \pm 3$ and $546 \pm 3 \mathrm{~nm}$ for HF-AuNPs and compound B AuNPs respectively was maintained in all the media. However, compound A-AuNPs (Fig 6iii) was less stable after 24 hrs resulting in a broadening of bands in the media. This lower stability can be attributed to the availability of the glucose moiety in a metal-organic framework of compound A-AuNPs. It seems the glucose became unstable due to isomerization to fructose over gold nanoparticles in aqueous media of BSA, glycine and cysteine. A similar report was published for sodium titanate nanotubes where glucose in aqueous media rapidly isomerized to fructose [20]. Also, the lower stability of compound A-AuNPs can be attributed to the neutral to alkaline $\mathrm{pH}$ used, which facilitated possible isomerization and epimerization in a reversible reaction of glucose to fructose and mannose respectively [24].

\subsection{Inhibition of $\alpha$-glucosidase and $\alpha$-amylase enzymes}

Enzymatic in vitro experiments for $\alpha$-glucosidase and $\alpha$-amylase inhibition at $\mathrm{IC}_{50}$ indicated higher activity for $\mathrm{HF}$ at $27.3 \pm 0.3 \mu \mathrm{g} / \mathrm{mL}$ than HF-AuNPs at $391.5 \pm 0.1 \mu \mathrm{g} / \mathrm{mL}$, but no activity for $\alpha$-amylase inhibition compared to HF-AuNPs ( $44.5 \pm 0.1 \mu \mathrm{g} / \mathrm{mL})$. Compound B and its AuNPs showed dual inhibitory potentials for both $\alpha$-glucosidase and $\alpha$-amylase enzymes, with $\mathrm{HB}(19.4 \pm 0.3 \mu \mathrm{g} / \mathrm{mL})$ slightly higher by two folds $(40.0 \pm 0.2 \mu \mathrm{g} / \mathrm{mL})$ for $\alpha$-glucosidase and nearly the same activity for $\alpha$-amylase at $25.1 \pm 0.3 \mu \mathrm{g} / \mathrm{mL}$ and $35.6 \pm 0.1 \mu \mathrm{g} / \mathrm{mL}$ respectively, (Table 1). The aglycone form (compound B) showed higher activity of and its AuNPs than the glycosidic one (compound A). This is similar to the report of Hamid et al., [15] on the structure-activity-relationship of compounds from Tinospora crispa plant evaluated for $\alpha$-glucosidase and $\alpha$-amylase enzymes inhibition [15] However, compound A is the least active sample but displayed a higher activity for $\alpha$-glucosidase than its nanoparticles. Both HA and its gold nanoparticles show no inhibition for $\alpha$-amylase enzymes (Table 1 ). This may be attributed to the glycosidic bond attached to the chalcone structure that raised the inhibition threshold of the amylase enzyme. HF and HF-AuNPs displayed relatively strong activity probably as a result of synergy between chalcones present and their nanoparticles as demonstrated by compound B and its AuNPs. Despite the higher activities of HF constituents over their gold nanoparticles as drug candidates, the ability of the spleen and liver to recognize and remove drugs from systemic circulation may affect drug delivery. Badeggi et al. [3] reported gold nanoparticles capped by the total extract, fractions of procyanidins dimer and trimer isolated Leucosidea sericea. In comparison, the AuNPs of the dimer was noted with higher inhibitory activity for $\alpha$-amylase while the AuNPs of the trimer showed higher inhibition for $\alpha$-glucosidase. Functionalized gold nanoparticles from HF constituents may be considered as an option for active drug targeting due to the inert and biocompatibility properties of gold. Overall, $\alpha$-glucosidase activities of samples were in the following order: compound $\mathrm{B}>\mathrm{HF}>$ compound B-AuNPs $>$ compound A $>$ compound A-AuNPs $>$ HF-AuNPs, while for $\alpha$-amylase activitieswere: compound B $>$ compound B-AuNPs $>$ HF-AuNPs.

\subsection{Glucose uptake activities of compounds and nanoparticles}

High blood glucose is known to be among the high-risk factors for cardiovascular diseases(CVD). Given the side effect of the prolonged use of synthetic drugs for the control of blood glucose, the aim of this study was to assess the activity of the crude extract, pure compounds and their nanoparticles on glucose uptake in mammalian cells. Fig. 9 shows that all the compounds, except for HF Crude and HB, seem to decrease the relative glucose uptake with significant p-values. A similar report by Rajarajeshwari show minimal glucose uptake by 3T3-Li adypocytes cells treated with gymnemic acid commonly found in Gymnema sylvestre and its synthesised gold nanoparticles (Rajarajeshwari et al., 2014). HF Crude increased relative glucose uptake significantly. However, this action may be due to a combination of compounds working synergistically to activate glucose 'pick-up' by insulin instead of a single compound providing the action. This further confirms our result from carbohydrate enzyme inhibition and the potential of the total extract and the compound helichrysetin of $H$. foetidum as potential drug candidates for the management of diabetes conditions.

\subsection{Cytotoxicity results}

To determine the cytotoxicity of the plant extract, compounds and nanoparticles, the HaCaT keratinocytes from the human skin were used. This is a non-cancerous cell line and will be able to indicate the safety and toxicity of the extracts, compounds and nanoparticles. Following treatments, the MTT assay was performed and the results show that the plant extract, compounds and nanoparticles differentially induced cytotoxicity on the HaCaT cells at concentrations of 20 to $100 \mu \mathrm{g} / \mathrm{mL}$ 
(Fig. 10). Previously, Maria et al. (Perde-schrepler et al., 2016) demonstrated that gold nanoparticles synthesized from polyphenol rich Cornelian Cherry fruits (Cornus mas) exhibited dose dependent toxicity on $\mathrm{HaCaT}$ and epidermoid carcinoma, A431 cells where the nanoparticles was less toxic to A431 cell than HACaT. In specifics, the $\mathrm{IC}_{50}$ obtained for HF and HF-AuNPs was $49.04 \mu \mathrm{g} / \mathrm{mL}$ and $29.87 \mu \mathrm{g} / \mathrm{mL}$ respectively making them the most cytotoxic to the cells (Fig. 10A). In addition, the HA-AuNPs also induced cytotoxicity in the cells with $\mathrm{IC}_{50}$ of $67.42 \mu \mathrm{g} / \mathrm{mL}$ while the compound HA showed slight toxicity to the cells (Fig. 10B). However, the compound HB, as well as the HB-AuNPs, had $\mathrm{IC}_{50} \mathrm{~s}$ greater than $100 \mu \mathrm{g} / \mathrm{mL}$ (Fig. 10B). Taken together, findings from this study gave an indication of the cytotoxicity of the plant material and compounds as well as their various nanoparticles. The compound HA was least cytotoxic and could be explored further.

\section{Conclusion}

In this article, plant-mediated synthesis of gold nanoparticles with total extract and pure compounds from $H$. foetidum is reported for the first time. Through successive column chromatography, helichrysin and helichrysetin compounds were successfully isolated and characterized among other constituents. Extract and isolates showed promising application as both reducing and capping agents for biosynthesis gold nanoparticles through different physicochemical techniques. The pure compounds show a better effect in the size reduction of gold nanoparticles than the total extract and will be valuable in therapeutic and biomedical application. In addition, the use of pure compounds isolated from the total extract allows for a better understanding of the mechanism of biosynthesis of gold nanoparticles and the systemic glucose utilization due to glucose phosphorylation and activities of glucose hydrolyzing enzymes in the cells. This study contributes to a possible novel blood glucose-lowering scafold developmed through the conjugation of metal NPs and natural chalcones. This conjugations have an inhibitory potential activities against $\alpha$-amylase and $\alpha$-glucosidase enzymes, and glucose uptake in vitro. It also paves way for further studies on animal studies to establish the use of $H$. foetidum and its gold nanoparticles against diabetes and glucose-induced oxidative stress.

\section{Declaration of Competing Interest}

The authors declare no conflict of interest.

\section{Acknowledgement}

We wish to acknowledge the South African Rooibos Council for the financial support towards the completion of this research. In addition, partial funding was provided by the South African Medical Research Council (SAMRC) through its Division of Research Capacity Development under funding received from the South African National Treasury. The content hereof is the sole responsibility of the authors and do not necessarily represent the official views of the SAMRC or the funders. Also, we acknowledge the NMR facility at the University of the Western Cape, Mr Hamza Alsayed of iThemba Labs for XRD and Dr Rajan Sharma for his contribution.

\section{References}

[1] N. Abdel-Raouf, N.M. Al-Enazi, I.B.M. Ibraheem, Green biosynthesis of gold nanoparticles using Galaxaura elongata and characterization of their antibacterial activity, Arab. J. Chem. 10 (2017) S3029-S3039, https://doi.org/10.1016/j. arabjc.2013.11.044.

[2] K. Aoki, H. Sato, Y. Terauchi, Usefulness of antidiabetic alpha-glucosidase inhibitors: a review on the timing of administration and effects on gut hormones, Endocr. J. 66 (5) (2019) 395-401.

[3] U.M. Badeggi, E. Ismail, A.O. Adeloye, S. Botha, A.A. Hussein, Green synthesis of gold nanoparticles capped with procyanidins from Leucosidea sericea as potential antidiabetic and antioxidant agents, Biomolecules 10 (452) (2020).
[4] L. Barcelos, G. Heiden, First record of Helichrysum foetidum (L.) Moench. (Asteraceae, Gnaphalieae) for South America, J. Biodiversity Data 13 (4) (2017) 331-334.

[5] A.F. Barrero, P. Arteaga, M.M. Herrador, ent-Kaurene diterpenoids from Helichrysum foetidum, Fitoterapia 69 (1) (1998) 83-84.

[6] M. Bhardwaj, P. Yadav, S. Dalal, S. Kumar, A review on ameliorative green nanotechnological approaches in diabetes management, Biomed. Pharmacother. 127 (April) (2020), https://doi.org/10.1016/j.biopha.2020.110198.

[7] F. Bohlmann, W.R Abraham., New diterpenes and other ingredients from Helichrysum calliconum and Helichrysum heterolasium, Phytochemistry 18 (5) (1979) 889-891.

[8] M. Danaei, M. Dehghankhold, S. Ataei, F.H. Davarani, R. Javanmard, A. Dokhani, S. Khorasani, M. Mozafari, Impact of particle size and polydispersity index on the clinical applications of lipidic nanocarrier systems, Pharmaceutics 10 (57) (2018) $1-17$.

[9] Y. Dong, B. Zhang, W. Sun, Y. Xing, Intervention of Prediabetes by Flavonoids From Oroxylum indicum, 2nd ed., Elsevier Inc, 2019 https://doi.org/10.1016/B978-012-813822-9.00036-9.

[10] A.M. Elbagory, C.N. Cupido, M. Meyer, A.A. Hussein, Large scale screening of southern african plant extracts for the green synthesis of gold nanoparticles using microtitre-plate method, Molecules 21 (1498) (2016) 1-20.

[11] N.G.E.R. Etsassala, Jelili A. Badmus, Tesfaye T. Waryo, Jeanine L. Marnewick, Christopher N. Cupido, Ahmed A. Hussein, Emmanuel I. Iwuoha, Alphaglucosidase and alpha-amylase inhibitory activities of novel abietane diterpenes from Salvia africana-lutea, Antioxidants 8 (10) (2019) 1-12.

[12] V. Ganesh Kumar, S. Dinesh Gokavarapu, A. Rajeswari, T. Stalin Dhas, V. Karthick, Z. Kapadia, T. Shrestha, I.A. Barathy, A. Roy, S Sinha, Facile green synthesis of gold nanoparticles using leaf extract of antidiabetic potent Cassia auriculata, Colloids Surf. B 87 (1) (2011) 159-163, https://doi.org/10.1016/j.colsurfb.2011.05.016.

[13] S. Gangadoo, A. Taylor-Robinson, J. Chapman, Nanoparticle and biomaterial characterisation techniques, Mater. Technol. 30 (B1) (2015) B44-B56.

[14] A. Ghorbani, Biomedicine \& pharmacotherapy mechanisms of antidiabetic effects of flavonoid rutin, Biomed. Pharmacother. 96 (September) (2017) 305-312.

[15] H.A. Hamid, M.M. Yusoff, M. Liu, M.R. Karim, $\alpha$-Glucosidase and $\alpha$-amylase inhibitory constituents of Tinospora crispa: Isolation and chemical profile confirmation by ultra-high performance liquid chromatography-quadrupole timeof-flight/mass spectrometry, J. Funct. Foods 16 (2015) 74-80, https://doi.org/ 10.1016/j.jff.2015.04.011.

[16] F. Ho Yen, A.M. Sri Nurestri, H.S. Yee, K. Saiful Anuar, Helichrysetin induces DNA damage that triggers JKN-mediated apoptosis in Ca Ski cells, Pharmacognosy Mag. 13 (52) (2017) 607-612.

[17] S. Honary, F. Zahir, Effect of zeta potential on the properties of nano-drug delivery systems - a review (Part 2), Trop. J. Pharmaceut. Res. 12 (2) (2013) 265-273.

[18] N. Jaradat, M. Qneibi, M. Hawash, A. Sawalha, S. Qtaishat, F. Hussein, Chemical composition, antioxidant, antiobesity, and antidiabetic effects of Helichrysum sanguineum (L.) Kostel. from Palestine, Arab. J. Sci. Eng. (2020), https://doi.org/ 10.1007/s13369-020-04707-z.

[19] Z. Kakam, A. M., K. Franke, J.C. Ndom, E. Dongo, T.N. Mpondo, L.A Wessjohann, Secondary metabolites from Helichrysum foetidum and their chemotaxonomic significance, Biochem. Syst. Ecol. 39 (2) (2011) 166-167, https://doi.org/ 10.1016/j.bse.2011.02.005.

[20] S. Kumar, D. Nepak, K. Kansal, Expeditious isomerization of glucose to fructose in aqueous media over sodium titanate nanotubes, R. Soc. Chem. Adv. 8 (2018) 30106-30114.

[21] K.Y. Loo, K.H. Leong, Y. Sivasothy, H. Ibrahim, K. Awang, Molecular insight and mode of inhibition of $\alpha$-glucosidase and $\alpha$-amylase by pahangensin A from Alpinia pahangensis RIDL, Chem. Biodivers. 16 (6) (2019).

[22] A.C.U. Lourens, A.M. Viljoen, F.R van Heerden, South African Helichrysum species: a review of the traditional uses, biological activity and phytochemistry, J. Ethnopharmacol. 119 (3) (2008) 630-652.

[23] P. Luc Van, D.K. Norbert, C. Jean, M. Viateur, N. Speciosa, H. Etienne, S Niceas, Isolation of flavonoids and a chalcone from Helicrysum odoratissimum, J. Nat. Prod. 52 (3) (1989) 629-633.

[24] Q. Luo, Y. Zhang, L. Qi, S.L. Scott, Glucose isomerization and epimerization over metal-organic frameworks with single-site active centers, ChemCatChem (11) (2019) 1903-1909, 2019.

[25] O. Lushchak, A. Zayachkivska, A. Vaiserman, Review article metallic nanoantioxidants as potential therapeutics for type 2 diabetes : a hypothetical background and translational perspectives, Oxidat. Med. Cell. Longevity (3407375) (2018) 1-9, 2018.

[26] F.A.E. Malolo, A.B. Nouga, A. Kakam, K. Franke, L. Ngah, O. Flausino, E. M. Mpondo, F. Ntie-Kang, J.C. Ndom, V. Bolzani, L Wessjohann, Proteaseinhibiting, molecular modeling and antimicrobial activities of extracts and constituents from Helichrysum foetidum and Helichrysum mechowianum (compositae), Chem. Cent. J. 9 (1) (2015), https://doi.org/10.1186/s13065-0150108-1.

[27] A. Maroyi, Medicinal uses, biological and phytochemical properties of Helichrysum foetidum (L.), Moench. (Asteraceae) 12 (7) (2019) 63-68.

[28] R. Mata, J.R. Nakkala, S.R. Sadras, Polyphenol stabilized colloidal gold nanoparticles from Abutilon indicum leaf extract induce apoptosis in HT-29 colon cancer cells, Colloids Surf. B 143 (2016) 499-510, https://doi.org/10.1016/j. colsurfb.2016.03.069.

[29] P.I. Oteiza, A.G. Erlejman, S.V Verstraeten, C.L Keen, Flavonoid-membrane interactions : a protective role of flavonoids at the membrane surface? Clin. Dev. Immunol. 12 (1) (2005) 19-25. 
[30] M.N. Sarian, Q.U. Ahmed, S. Zaiton, M. So, A.M. Alhassan, S. Murugesu, V. Perumal, S. Nurul, A. Syed, A. Khatib, J. Latip, Antioxidant and antidiabetic effects of flavonoids : a structure-activity relationship based study, BioMed. Res. Int. Volume 2017 (2017) 1-14.

[31] M. Sengani, A.M. Grumezescu, V.D. Rajeswari, Recent trends and methodologies in gold nanoparticle synthesis - a prospective review on drug delivery aspect,

OpenNano 2 (July) (2017) 37-46, https://doi.org/10.1016/j.onano.2017.07.001.

[32] S. Süzgeç-Selçuk, A.S. Birteksöz, Flavonoids of Helichrysum chasmolycicum and its antioxidant and antimicrobial activities, S. Afr. J. Bot. 77 (1) (2011) 170-174, https://doi.org/10.1016/j.sajb.2010.07.017.

[33] V. Thipe, K. Panjtan Amiri, P. Bloebaum, A.R. Karikachery, M. Khoobchandani, K. K. Katti, S.S. Jurisson, K.V. Katti, Development of resveratrol-conjugated gold nanoparticles: interrelationship of increased resveratrol corona on anti-tumor efficacy against breast, pancreatic and prostate cancers, Int. J. Nanomed. 14 (2019) 4413-4428.
[34] B. Tirillini, L. Menghini, L. Leporini, N. Scanu, S. Marino, G. Pintore, V.A. Saffi, U. Pu, Antioxidant activity of methanol extract of Helichrysum foetidum Moench, Nat. Prod. Res. 27 (16) (2012) 14.

[35] H. Tsuchiya, Structure-dependent membrane interaction of flavonoids associated with their bioactivity, Food Chem. 120 (4) (2010) 1089-1096, https://doi.org/ 10.1016/j.foodchem.2009.11.057.

[36] M. Venkatachalam, K. Govindaraju, A. Mohamed Sadiq, S. Tamilselvan, V. Ganesh Kumar, G. Singaravelu, Functionalization of gold nanoparticles as antidiabetic nanomaterial, Spectrochimica Acta - Part A: Mol. Biomol. Spectrosc. 116 (2013) 331-338, https://doi.org/10.1016/j.saa.2013.07.038.

[37] W.G. Wright, South African plant extractives. Part 11 Helichrysin, a new chalcone glucoside from a Helichrysum species, J. Chem. Soc., Perkin Trans. 1 (1) (1976) 1819-1820.

[38] G. Zhan, J. Huang, L. Lin, W. Lin, K. Emmanuel, Q. Li, Synthesis of gold nanoparticles by Cacumen Platycladi leaf extract and its simulated solution: toward the plant-mediated biosynthetic mechanism, J. Nanopart. Res. 13 (10) (2011) 4957-4968. 